\title{
PENGARUH KUALITAS PELAYANAN TERHADAP LOYALITAS KONSUMEN MELALUI KEPUASAN KONSUMEN PADA TOKO MANDIRI TEXTILE PASAR RAYA PADANG
}

\author{
Misi Ariansyah \\ Dosen Fakultas Ekonomi Universitas Tamansiswa Padang \\ Email:misiariansyah@gmail.com \\ Sepris Yonaldi \\ Dosen Fakultas Ekonomi Universitas Tamansiswa Padang \\ Email: seprisyonaldi@gmail.com \\ Hafrizal Okta Ade Putra \\ Dosen Fakultas Ekonomi Universitas Tamansiswa Padang \\ Email: hafrizalokta@gmail.com
}

\begin{abstract}
This study aims to determine how much effect of service quality to customer loyalty through customer satisfaction on toko Mandiri Textile pasar raya padang. Sample method used was simple random sampling. samples used to represent the population is of 100 respondents. data collection methods used are observation, questionnaires, and library. Based on the analysis path used satisfaction provides an increase of 30.3\%, consumer loyalty providing increased by $22.9 \%$ and customer satisfaction by 9.8\%. T test performed showed that these three variables significantly influence consumer loyalty. the value of the variable quality of service to customer satisfaction with the value of $t$ test $>t$ table $(2,491>1,660)$. service quality on custor... loyalty with value $t$ test $>t$ table (7594> 1.660). satisfaction to loyalty to the value of $t$ test $>t$ table (2.925> 60). service quality through customer satisfaction to increase loyalty konsmen by t test $>$ t table (7582> $1.66 \mathrm{C}$.
\end{abstract}

Keywords: service quality, Customer Loyalty and Customer Satisfaction

\section{PENDAHULUAN}

\section{Latar Belakang Penelitian}

Kota Padang merupakan salah satu daerah yang strategis untuk membangun sebuah bisnis, salah satunya karena memiliki jumlah penduduk yang paling banyak di Sumatera Barat (1.054.000 jiwa), sebagian besar masyarakatnya adalah pedagang, dan beberapa tahun belakangan ini ekspansi bisnis sangat meningkat. Di Kota Padang, banyak toko yang menjual produk yang sama, seperti Toko Cahaya Textile, Toko Barokah, Toko PGD Textile, dan masih banyak Toko Textile lainya. Masing-masing toko tersebut sama-sama dalam bidang textile yang berjenis produk yaitu gorden. Kesamaan dalam produk tersebut ini akan memunculkan persaingan. Salah satunya Toko Mandiri Textile Pasar Raya Padang, yang bergerak di bidang textile dengan jenis produk gorden. Toko Mandiri Textile merupakan perusahaan perseorangan yang berdiri semenjak tahun 1998.

Berdasarkan hasil survey awal penulis lakukan pada konsumen Toko Mandiri Textile Pasar Raya Padang, mereka mengatakan bahwa kualitas layanan yang diberikan sudah cukup baik, mampu memenuhi kebutuhan konsumen dengan tersedianya bahan-bahan yang berkualitas, serta mampu memberikan pelayanan yang tepat dan sesuai dengan kebutuhan konsumen. Namun beberapa konsumen mengatakan bahwa kualitas pelayanan yang diberikan oleh Toko Mandiri Textile Pasar Raya Padang kurang baik karena belum lengkapnya jenis barang yang tersedia, banyak barang rusak, desain kurang bagus, dan kurang tanggapnya 
karyawan dalam menyelesaikan keluhan konsumen, penilaian konsumen terhadap kualitas layanan ini mempengaruhi tingkat kepuasan konsumen, untuk meningkatkan loyalitas konsumen tentu adanya kepuasan dari konsumen, agar berhasil dalam memenangkan persaingan, harus dapat mempertahankan konsumennya untuk menjadi konsumen yang tetap, dengan kata lain perusahaan harus dapat meningkatkan kepuasan konsumen agar loyalitas konsumen bisa terjadi.

Berdasarkan gambaran data di atas dapat diketahui bahwa ada sedikit keganjalan atau keluhan-keluhan dari konsumen terhadap pelayanan yang diberikan oleh Toko Mandiri Textile Pasar Raya Padang. Keluhan yang dipengaruhi dalam hal pelayanan yang diterima oleh konsumen. Dengan adanya keluhan konsumen terhadap kualitas pelayanan tersebut, maka dengan itu perusahaan harus meningkatkan kualitas pelayanan yang diberikan kepada konsumen atau belum maksimalnya pelayanan yang diberikan kepada konsumen. Hal ini dapat memberikan dampak negatif bagi perusahaan, maka dari itu harus tetap berusaha meningkatkan pelayanan agar konsumen merasa puas dengan kualitas pelayanan yang diberikan sehingga loyalitas konsumen pada Toko Mandiri Textile Pasar Raya Padang akan menajadi meningkat.

Berdasarkan dari latar belakang tersebut penulis tertarik untuk melakukan penelitian dengan judul Pengaruh Kualitas Pelayanan Terhadap Loyalitas Konsumen Melalui Kepuasan Konsumen Pada Toko Mandiri Textile Pasar Raya Padang.

\section{Rumusan Masalah}

1. Bagaimana pengaruh kualitas pelayanan terhadap kepuasan konsumen pada Toko Mandiri Textile Pasar Raya Padang?

2. Bagaimana pengaruh kualitas pelayanan terhadap loyalitas konsumen pada Toko Mandiri Textile Pasar Raya Padang?

3. Bagaimana pengaruh kepuasan konsumen terhadap loyalitas konsumen pada Toko Mandiri Textile Pasar Raya Padang?

4. Bagaimana pengaruh kualitas pelayanan melalui kepuasan konsumen terhadap loyalitas konsumen pada Toko Mandiri Textile Pasar Raya Padang?

\section{Tujuan Penelitian}

1. Untuk mengetahui dan menganalisis pengaruh kualitas pelayanan terhadap kepuasan konsumen pada Toko Mandiri Textile Pasar Raya Padang.

2. Untuk mengetahui dan menganalisis pengaruh kualitas pelayanan terhadap loyalitas konsumen pada Toko Mandiri Textile Pasar Raya Padang.

3. Untuk mengetahui dan menganalisis pengaruh kepuasan konsumen terhadap loyalitas pelanggan pada Toko Mandiri Textile Pasar Raya Padang.

4. Untuk mengetahui dan menganalisis pengaruh kualitas pelayanan melalui kepuasan konsumen terhadap loyalitas konsumen pada Toko Mandiri Textile Pasar Raya Padang.

\section{LANDASAN TEORI}

\subsection{Kualitas Pelayanan}

Menurut Tjiptono (2011:59) kualitas layanan adalah "tingkat keunggulan yang diharapkan dan pengendalian atas tingkat keunggulan tersebut untuk memenuhi keinginan pelanggan, sedangkan menurut Lovelock (2010:96) kualitas pelayanan adalah seberapa jauh perbedaan antara kenyataan dan harapan konsumen atas layanan yang mereka terima.

Menurut Lovelock (2011:98), konsumen akan menilai kualitas jasa melalui lima dimensi pelayanan sebagai tolak ukurnya adalah sebagai berikut : 
1. Keberwujudan (tangible): Kemampuan suatu perusahaan dalam menunjukan eksisitensinya kepada pihak eksternal. Penampilan dan kemampuan, sarana dan prasarana fisik perusahaan yang dapat diandalkan merupakan bukti nyata dari pelayanan yang diberikan oleh pemberi jasa.

2. Empati (emphaty): Memberikan perhatian yang tulus dan bersifat individual atau pribadi yang diberikan kepada para konsumen dengan berupaya memahami keinginan konsumen.

3. Keandalan (feliability): Kemampuan perusahaan untuk memberikan pelayanan sesuai dengan yang dijanjikan serta akurat dan terpercaya. Kinerja harus sesuai dengan harapan konsumen yang berarti ketepatan waktu, pelayanan, yang sama untuk semua konsumen tanpa kesalahan, sikap yang simpatik, dan dengan akurasi yang tinggi.

4. Daya tanggap (responsiveness): Suatu kebijakan untuk membantu dan memberikan pelayanan yang cepat (responsif) dan tepat kepada konsumen, dengan penyampaian informasi yang jelas.

5. Jaminan (assurance): Pengetahuan, kesopanan, dan kemampuan para pegawai perusahaan untuk menumbuhkan rasa percaya para konsumen kepada perusahaan. Hal ini meliputi komunikasi, kredibilitas, keamanan, kompetensi, dan sopan santun.

\subsection{Loyalitas Konsumen}

Menurut Nugroho (2011:16), loyalitas adalah pilihan yang dilakukan konsumen untuk membeli merek tertentu dibandingkan merek yang lain dalam kategori produk. Menurut Griffin (2010:129), mendefinisikan loyalitas lebih mengacu pada wujud perilaku dari unitunit pengambilan keputusan untuk melakukan pembelian secara terus menerus terhadap barang/jasa suatu perusahaan yang dipilih.

Menurut Griffin (2010:32), indikator dari loyalitas konsumen adalah sebagai berikut :

1. Melakukan pembelian ulang secara teratur: Konsumen melakukan pembelian secara continue pada suatu produk tertentu.

2. Membeli antar lini produk atau jasa: Konsumen tidak hanya membeli jasa dan produk utama tetapi konsumen juga membeli lini produk dan jasa dari perusahaan yang sama.

3. Mereferensikan kepada orang lain: Dimana konsumen melakukan komunikasi dari mulut ke mulut (word of mouth) berkenaan dengan produk tersebut.

4. Menunjukan kekebalan terhadap tarikan dari pesaing: Konsumen menolak untuk menggunakan produk atau jasa alternatif yang ditawarkan oleh pesaing.

\subsection{Kepuasan Konsumen}

Menurut Tjiptono (2011:352), dari keseluruhan kegiatan yang dilakukan oleh sebuah perusahaan, pada akhirnya akan bermuara pada nilai yang akan diberikan oleh konsumen mengenai kepuasan yang dirasakan. Kepuasan yang sesungguhnya dirasakan konsumen sebenarnya adalah persepsi pelanggan terhadap kualitas produk tersebut. Menurut Ishak dan Luthfi (2011:58), mendefinsikan kepuasan konsumen sebagai hasil evaluasi menyeluruh konsumen atas kinerja produk yang dikonsumsinya.

Menurut Kotler (2011), menjelaskan bahwa kepuasan konsumen dibagi menjadi 3 (tiga) dimensi adalah sebagai berikut :

1. Kesesuaian harapan: Merupakan tingkat kesesuaian antara kinerja produk yang diharapkan oleh konsumen dengan yang dirasakan oleh konsumen.

2. Minat berkunjung kembali: Merupakan kesedian konsumen untuk berkunjung kembali atau melakukan pembelian ulang terhadap produk terkait.

3. Kesediaan merekomendasikan: Merupakan kesediaan konsumen untuk merekomendasikan produk yang telah dirasakannya kepada teman atau keluarga. 


\subsection{Hubungan Antar Variabel}

\subsubsection{Pengaruh Kualitas Pelayanan Terhadap Kepuasan Konsumen}

Kualitas pelayanan harus menjadi fokus utama perusahaan. Persaingan yang sangat ketat, dengan semakin banyak produsen yang terlibat dalam pemenuhan kebutuhan dan keinginan konsumen menyebabkan setiap perusahaan harus mampu menempatkan orientasi pada kepuasan pelanggan sebagai tujuan utama. Terciptanya kepuasan konsumen adalah salah satu upaya dari perusahaan untuk dapat terus bertahan dan memenangkan persaingan dalam pasar yang ada (Tjiptono, 2011).

\subsubsection{Pengaruh Kepuasan Konsumen Terhadap Loyalitas Konsumen}

Kepuasan konsuman adalah suatu keadaan dimana keinginan, harapan dankebutuhan konsuman dipenuhi. Suatu pelayanan dinilai memuaskan bilapelayanan tersebut dapat memenuhi kebutuhan dan harapan konsumen. Pengukuran kepuasan konsuman merupakan elemen penting dalam menyediakan pelayanan yang lebih baik, lebih efisien dan lebih efektif, apabila konsuman merasa tidak puas terhadap suatu pelayanan yang disediakan, maka pelayanan tersebut dapat dipastikan tidak efektif dan tidak efisien. Dengan adanya kepuasan konsumen maka akan dapat menciptakan loyalitas pelanggan. Sesuai dengan teori Kotler (2011:236), bahwa kepuasan atau ketidakpuasan konsumen akan mempengaruhi perilaku konsumen.

\subsubsection{Pengaruh Kualitas Pelayanan Terhadap Loyalitas Konsumen}

Untuk loyalitas pelanggan terhadap layanan, ada dua hal pokok yang saling berkaitan erat yaitu harapan pelanggan terhadap kualitas layanan (expected quality) dan persepsi pelanggan terhadap kualitas layanan (perceived quality). Pelanggan selalu menilai suatu layanan yang diterima dibandingkan dengan apa yang diharapkan atau diinginkan (Parasuraman, 2010). Penelitian yang dilakukan oleh Desmiati (2010), menyatakan bahwa kualitas pelayanan berpengaruh terhadap loyalitas pelanggan.

\subsubsection{Pengaruh Kualitas Pelayanan, Kepuasan Konsumen Terhadap Loyalitas Konsumen}

Kualitas pelayanan harus menjadi fokus utama perhatian perusahaan. Persaingan yang sangat ketat, dengan semakin banyak produsen yang terlibat dalam pemenuhan kebutuhan dan keinginan konsumen menyebabkan setiap perusahaan harus mampu menempatkan orientasi pada kepuasan pelanggan sebagai tujuan utama. Kepuasan konsuman suatu keadaan dimana keinginan, harapan dankebutuhan konsuman dipenuhi. Pengukuran kepuasan konsuman merupakan elemen penting dalam menyediakan pelayanan yang lebih baik, lebih efisien dan lebih efektif, apabila konsuman merasa tidak puas terhadap suatu pelayanan yang disediakan, maka pelayanan tersebut dapat dipastikan tidak efektif dan tidak efisien. Dengan adanya kepuasan konsumen maka akan dapat menciptakan loyalitas pelanggan. Sesuai dengan teori Kotler (2011:236), bahwa kepuasan atau ketidakpuasan konsumen akan mempengaruhi perilaku konsumen.

\subsection{Kerangka Konseptual}

Loyalitas konsumen dalam menggunakan jasa yang ditawarkan dapat dijadikan sebagai bahan masukan kepada pihak perusahaan untuk memperbaiki dan meningkatkan kualitas pelayanan yang diberikan. Kepuasan konsumen dapat dipenuhi melalui kualitas pelayanan yang kompetitif sehingga konsumen akan melanjutkan transaksi dengan perusahaan tersebut. Kepuasan konsumen akan terpenuhi apabila mereka memperoleh apa yang mereka inginkan maka akan semakin tinggi tingkat loyalitas konsumen. Berdasar 
uraian variabel-variabel di atas kerangka pemikiran-pemikiran ini dapat digambarkan sebagai berikut :

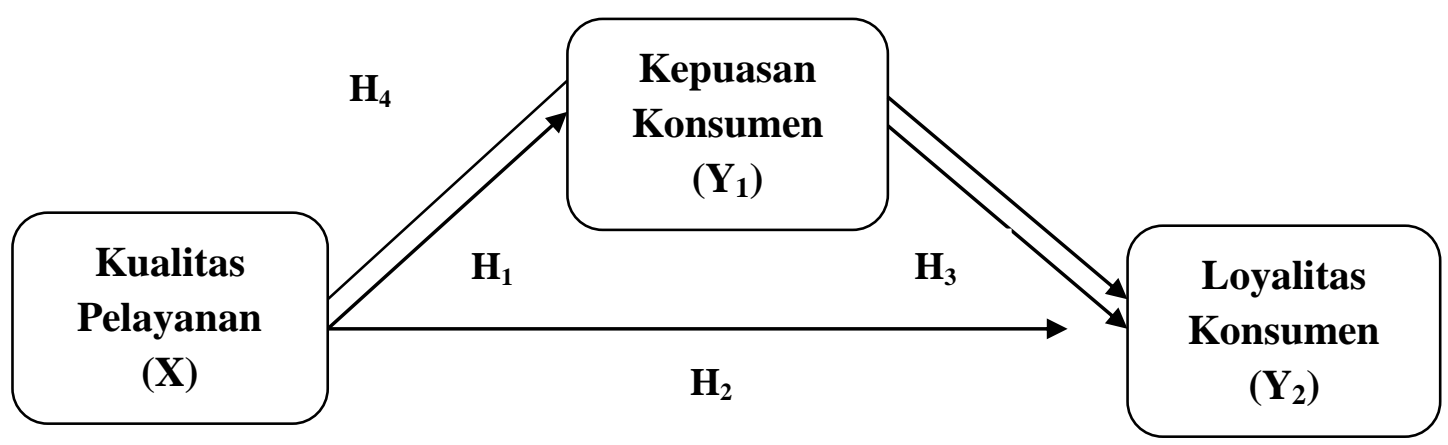

Gambar 2.1

Kerangka Konseptual

\section{Hipotesis}

$\mathrm{H}_{1}$ : Diduga kualitas pelayanan berpengaruh signifikan terhadap kepuasan konsumen pada Toko Mandiri Textile Pasar Raya Padang.

$\mathrm{H}_{2}$ : Diduga kualitas pelayanan berpengaruh signifikan terhadap loyalitas konsumen pada Toko Mandiri Textile Pasar Raya Padang.

$\mathrm{H}_{3}$ : Diduga kepuasan konsumen berpengaruh signifikan terhadap loyalitas konsumen pada Toko Mandiri Textile Pasar Raya Padang.

$\mathrm{H}_{4}$ : Diduga kualitas pelayanan melalui kepuasan konsumen berpengaruh signifikan terhadap loyalitas konsumen pada Toko Mandiri Textile Pasar Raya Padang.

\section{METODOLOGI PENELITIAN}

\subsection{Jenis Metodologi Penelitian}

Metodologi penelitian yang digunakan dalam penelitian ini adalah penelitian kuantitatif. Penelitian kuantitatif adalah metode penelitian yang berlandaskan positivisme, digunakan untuk meneliti pada populasi atau sampel tertentu, pengumpulan data menggunakan instrumen penelitian, analisis data bersifat kuantitatif/statistik, dengan tujuan untuk menguji hipotesis yang telah ditetapkan (Sugiyono, 2012:8).

\subsection{Populasi dan Sampel Penelitian}

Populasi dalam penelitian ini adalah seluruh konsumen Toko Mandiri Textil Pasar Raya Padang, yang jumlah populasinya tidak diketahui. Menurut Sarwono (2009:319), sampel merupakan sub dari seperangkat elemen yang dipilih untuk dipelajari. Sekaran (2002:252), mengemukakan penentuan jumlah sampel sebagai berikut :

1. Sebaiknya ukuran sampel diantara 30 sampai 500 elemen.

2. Jika sampel dipecah lagi ke dalam subsampel, jumlah minimum subsampel harus 30 .

3. Pada penelitian multivariate (termasuk analisis regresi multivariate) ukuran sampel harus beberapa kali lebih besar ( 10 kali) dari jumlah variabel yang akan dianalisis.

4. Untuk penelitian eksperimen yang sederhana, dengan pengendalian yang ketat ukuran sampel bisa diantara 10 sampai dengan 20 elemen.

Berdasarkan metode tersebut banyaknya sampel yang digunakan dalam penelitian adalah 100 orang yang merupakan konsumen Toko Mandiri Textile Pasar Raya Padang. Pengambilan sampel dilakukan dengan simple random sampling yaitu unit-unit sampling individual yang dipilih secara acak (Sarwono, 2009:322). 


\subsection{Teknik Pengumpulan Data}

1. Observasi

2. Angket

3. Studi kepustakaan

\subsection{Teknik Analisis Data}

\subsection{Analisa Deskriptif}

Analisis deskriptif dilakukan dengan menggunakan tabel frekuensi untuk melihat penyebaran data dalam suatu variabel. Analisis deskriptif ini berguna untuk melihat gambar baik rata-rata maupun penyebaran dari hasil yang telah diperoleh oleh kuisioner.

\subsubsection{Uji Instrument}

1. Uji Validitas

Suatu instrumen dikatakan valid apabila mampu mengukur apa yang diinginkan serta dapat mengungkapkan data yang terkumpul tidak menyimpang dari gambaran variabel yang dimaksud. Instrumen yang valid berarti alat ukur yang diunakan untuk mendapatkan data (mengukur) itu valid. Untuk syarat minimum dianggap valid kalau $\mathrm{r}=0,300$.

2. Uji Reliabilitas

Uji reliabilitas adalah suatu alat untuk mengukur suatu angket yang merupakan indikator dari suatu variabel atau konstruk. Suatu angket dikatakan reliabel atau handal jika jawaban seseorang terhadap pernyataan adalah konsisten atau stabil dari waktu ke waktu. Suatu konstruk atau variabel dikatakan reliabel jika memberikan nilai Cronbach Alpha > 0,600 (Ghozali, 2005:41).

\subsubsection{Analisa Jalur}

Menurut Paul (2008), analisis jalur merupakan pengembangan langsung bentuk regresi berganda dengan tujuan untuk memberikan estimasi tingkat kepentingan dan signifikansi hubungan sebab akibat hipotetikal dalam seperangkat variabel untuk itu akan digunakan program analisis SPSS. SPSS adalah suatu software yang berfungsi untuk menganalisis data, melakukan perhitungan statistik baik untuk statistik parametrik maupun non-parametrik dengan basis windows. Dalam penelitian ini akan menggunakan program SPSS for Windows versi 20.

Asumsi analisis jalur mengikuti asumsi umum regresi linear, yaitu:

1. Model regresi harus layak. Kelayakan ini diketahui jika angka signifikansi pada ANOVA sebesar $<0.05$

2. Prediktor yang digunakan sebagai variabel bebas harus layak. Kelayakan ini diketahui jika angka Standard Error of Estimate < Standard Deviation

3. Koefisien regresi harus signifikan. Pengujian dilakukan dengan Uji t. Koefisien regresi signifikan jika $t_{\text {hitung }}>\mathrm{t}_{\text {tabel }}$ (nilai kritis)

4. Tidak boleh terjadi multikolinieritas, artinya tidak boleh terjadi korelasi yang sangat tinggi atau sangat rendah antar variabel bebas.

5. Tidak terjadi otokorelasi, atau terjadi otokorelasi jika angka Durbin dan Watson kurang dari 1 atau lebih dari 3.

\section{Tipe Model-model Jalur}

Analisis jalur dalam penelitian ini menjelaskan pengaruh antar variabel langsung dan tidak langsung sebagai dapat dijelaskan bahwa di dalam analisis jalur tersebut ada 3 macam pengaruh yaitu pengaruh langsung (Direct Effect atau DE), pengaruh tidak langsung (Indirect Effect atau IE) dan pengaruh total (Total Effect). 
Berikut ini diuraikan pembahasan dari hasil perhitungan ke 3 pengaruh tersebut di atas.

1. Untuk menghitung pengaruh langsung (DE), dengan formula sebagai berikut :

a. Pengaruh kualitas pelayanan terhadap kepuasan konsumen.

$\mathrm{X} \longrightarrow \mathrm{Y}_{1}=\mathrm{p} 2=(\mathrm{DE} 1)$

b. Pengaruh kualitas pelayanan terhadap loyalitas konsumen.

$\mathrm{X} \longrightarrow \mathrm{Y}_{2}=\mathrm{p} 1=(\mathrm{DE} 2)$

c. Pengaruh kepuasan konsumen terhadap loyalitas konsumen.

$\mathrm{Y}_{1} \longrightarrow \mathrm{Y}_{2}=\mathrm{p} 3=(\mathrm{DE} 3)$

2. Pengaruh Tidak Langsung (IE)

Untuk menghitung pengaruh tidak langsung (IE) kualitas pelayanan melalui kepuasan konsumen terhadap loyalitas konsumen digunakan formula sebagai berikut :

$\mathrm{X} \nRightarrow \mathrm{Y} 1 \nRightarrow \mathrm{Y} 2=\mathrm{p} 2 \times \mathrm{p} 3=(\mathrm{IE})$

3. Pengaruh Total (Total Effect)

Pengaruh total (total effect) adalah besarnya nilai pengaruh total variabel kualitas pelayanan melalui kepuasan konsumen terhadap loyalitas konsumen. Besarnya pengaruh ini dapat dicari dengan mengalikan koefisien jalur yang terbentuk (p) dengan koefisien korelasi Pearson Zero Order.

\subsubsection{Uji Hipotesis}

Uji t

Digunakan untuk mengetahui pengaruh dari masing-masing variabel, vaik variabel bebas terhadap variabel terikat tersebut yang signifikan secara statistik. Menggunakan uji masing-masing koefisien regresi variabel bebas apakah mempunyai pengaruh yang bermakna atau tidak terhadap variabel terikat. (Sugiyono, 2012:184).

\section{HASIL PENELITIAN DAN PEMBAHASAN}

\subsection{Hasil Analisis Jalur}

Dalam penelitian ini akan menggunakan program SPSS for Windows versi 20. Berdasarkan hasil penelitian diketahui seperti tampak pada tabel 16 berikut :

Tabel 4.1 Pengaruh Antar Variabel

\begin{tabular}{llllll}
\hline Variabel & $\mathrm{B}$ & $\mathrm{T}$ & $\mathrm{Sig}$ & $\mathrm{p}$ & Ket. \\
\hline Kualitas Pelayanan_Kepuasan Konsumen & 0.717 & 2.491 & 0,004 & 0,05 & Signifikan \\
Kualitas Pelayanan_Loyalitas Konsumen & 0.543 & 7.599 & 0,000 & 0,05 & Signifikan \\
KepuasanKonsumen_Loyalitas Konsumen & 0.228 & 2.925 & 0,004 & 0,05 & Signifikan \\
\hline Sumber: Data primer yang diolah, 2016 & & & & &
\end{tabular}

Berdasarkan Tabel 4.1 diketahui bahwa nilai koefisien jalur p1, p2, p3 yang terjadi adalah signifikan. Pengaruh ini dibuktikan dari nilai signifikansi dengan uji regresi. Adapun nilai sig. uji regresi disebut signifikan jika nilai signifikansi lebih kecil dari 0,05. Berdasarkan tabel di atas dapat dibuat diagram nilai-nilai koefisien jalur yang telah dilakukan tersebut dapat digambarkan sebagai berikut :

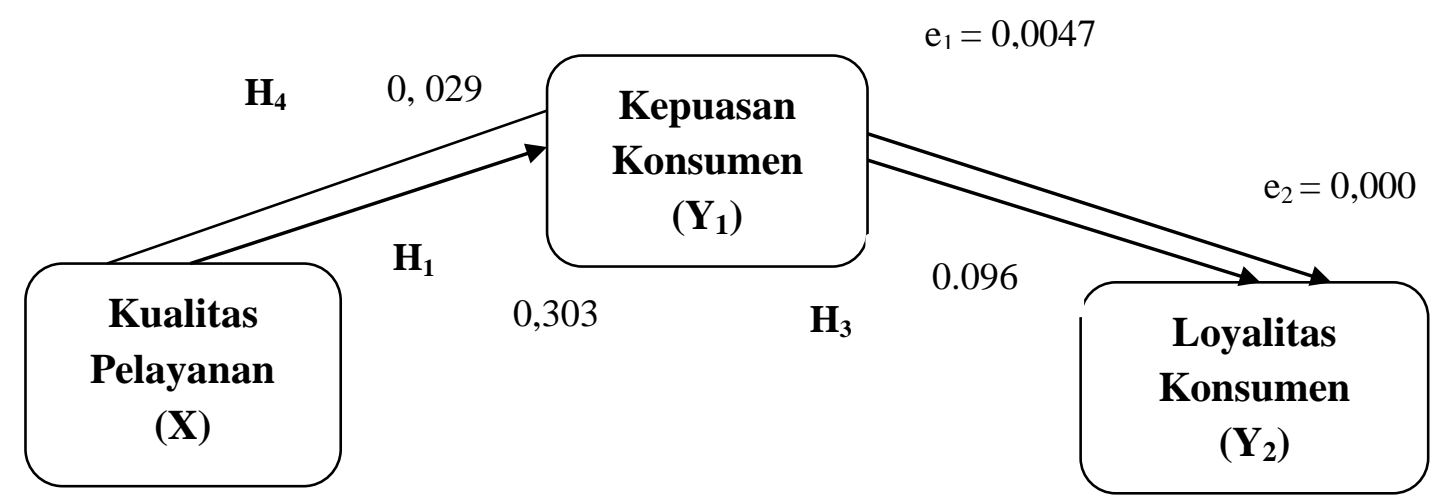




\section{$\begin{array}{ll}\mathbf{H}_{2} & 0.229\end{array}$ \\ Gambar 2. \\ Diagram Nilai Koefisien Jalur}

Berdasarkan hasil analisis di atas, dapat dijelaskan bahwa di dalam analisis jalur tersebut ada 3 macam pengaruh yaitu pengaruh langsung (direct effect atau DE), pengaruh tidak langsung (indirect effect atau IE) dan pengaruh total (total effect). Untuk menghitung pengaruh langsung atau $\mathrm{DE}$, digunakan formula sebagai berikut :

1. Pengaruh kualitas pelayanan terhadap kepuasan konsumen.

$\mathrm{X} \longrightarrow \mathrm{Y}_{1}=\mathrm{p} 1=(\mathrm{DE} 1)$

$0,717 \times 0,423=0,303$

Keterangan :

$\mathrm{X}=$ Kualitas pelayanan

$\mathrm{Y}_{1}=$ Kepuasan konsumen

$\mathrm{P} 1$ = Pengaruh langsung pertama

2. Pengaruh kualitas pelayanan terhadap loyalitas konsumen.

$\mathrm{X} \longrightarrow \mathrm{Y}_{2}=\mathrm{p} 2=(\mathrm{DE} 2)$

$0,543 \times 0,423=0,229$

Keterangan :

$\mathrm{X}=$ Kualitas pelayanan

$\mathrm{Y}_{2}=$ Loyalitas konsumen

$\mathrm{P} 2$ = Pengaruh langsung kedua

3. Pengaruh kepuasan konsumen terhadap loyalitas konsumen.

$\mathrm{Y}_{1} \longrightarrow \mathrm{Y}_{2}=\mathrm{p} 3=(\mathrm{DE} 3)$

$0,228 \times 0,423=0,096$

Keterangan :

$\mathrm{Y}_{1}=$ Kepuasan konsumen

$\mathrm{Y}_{2}=$ Loyalitas konsumen

P3 = Pengaruh langsung ketiga

4. Pengaruh tidak langsung (indirect effect atau IE)

Untuk menghitung pengaruh tidak langsung (IE) kualitas pelayanan melalui kepuasan konsumen terhadap loyalitas konsumen digunakan formula sebagai berikut :

$\mathrm{X} \longrightarrow \mathrm{Y}_{1} \longrightarrow \mathrm{Y}_{2}=\mathrm{p} 2 \times \mathrm{p} 3=0,303 \times 0,096=0,029$ (IE)

Keterangan :

$\mathrm{X}=$ Kualitas pelayanan

$\mathrm{Y}_{1}=$ Kepuasan konsumen

$\mathrm{Y}_{2}=$ Loyalitas konsumen

P2 = Pengaruh langsung kedua

P3 = Pengaruh langsung ketiga

5. Pengaruh total (total effect)

Berdasarkan uji Zero Order Correlation, rangkuman hasilnya dapat disajikan pada tabel 17. 
Tabel 4.2 Zero Order Correlation

\begin{tabular}{llrrr}
\hline \multicolumn{5}{c}{ Correlations } \\
\hline & $\begin{array}{c}\text { Loyalitas_ } \\
\text { Konsumen }\end{array}$ & $\begin{array}{c}\text { Kualitas_ } \\
\text { Pelayanan }\end{array}$ & $\begin{array}{r}\text { Kepuasan_ } \\
\text { Konsumen }\end{array}$ \\
\hline Pearson & Loyalitas_Konsumen & 1.000 & .609 & .283 \\
Correlation & Kualitas_Pelayanan & .609 & 1.000 &. $\mathbf{0 9 2}$ \\
& Kepuasan_Konsumen & .283 & .092 & 1.000 \\
Sig. (1-tailed) & Loyalitas_Konsumen &. & .000 & .002 \\
& Kualitas_Pelayanan & .000 &. & .181 \\
& Kepuasan_Konsumen & .002 & .181 &. \\
N & Loyalitas_Konsumen & 100 & 100 & 100 \\
& Kualitas_Pelayanan & 100 & 100 & 100 \\
& Kepuasan_Konsumen & 100 & 100 & 100 \\
\hline \multirow{2}{*}{ Sumber : Data primer yang diolah, 2016 } & & &
\end{tabular}

Berdasarkan total effect menunjukkan besarnya pengaruh langsung antara variabel adalah sebagai berikut :

1. Variabel kualitas pelayanan terhadap kepuasan konsumen (DE1) adalah sebesar 0.303 .

2. Variabel kualitas pelayanan terhadap loyalitas konsumen (DE2) adalah sebesar 0,229.

3. Variabel kepuasan konsumen terhadap loyalitas konsumen (DE3) adalah sebesar 0,096 .

4. Sedangkan pengaruh tidak langsung (IE) kualitas pelayanan melalui kepuasan konsumen terhadap loyalitas konsumen adalah sebesar 0,029 .

\subsection{Uji Hipotesis}

Uji t

Digunakan untuk mengetahui pengaruh dari masing-masing variabel, baik variabel bebas terhadap variabel terikat tersebut yang signifikan secara statistik. Menggunakan uji masing-masing koefisien regresi variabel bebas apakah mempunyai pengaruh yang bermakna atau tidak terhadap variabel terikat (Sugiyono, 2012:184).

\section{Pengaruh Variabel Kualitas Pelayanan Terhadap Kepuasan Konsumen Konsumen (H1)}

Tabel 4.17 Hasil Uji t (Parsial)

\begin{tabular}{|c|c|c|c|c|c|}
\hline \multirow[b]{3}{*}{ Model } & \multicolumn{3}{|c|}{ Coefficients $^{\mathrm{a}}$} & \multirow[b]{3}{*}{$\mathrm{t}$} & \multirow[b]{3}{*}{ Sig. } \\
\hline & \multicolumn{2}{|c|}{$\begin{array}{c}\text { Unstandardized } \\
\text { Coefficients }\end{array}$} & $\begin{array}{l}\text { Standardized } \\
\text { Coefficients }\end{array}$ & & \\
\hline & $\mathrm{B}$ & Std. Error & Beta & & \\
\hline 1 (Constant) & 2.999 & 4.494 & & .445 & .660 \\
\hline Kualitas_Pelayanan & .717 & .514 & .157 & 2.491 & .004 \\
\hline
\end{tabular}

Sumber: Data primer yang diolah, 2016 
Variabel kualitas pelayanan (X) berpengaruh secara positif dan signifikan terhadap kepuasan konsumen Toko Mandiri Textile Pasar Raya Padang. Hal ini terlihat dari signifikan $0,004<0,05$ nilai $\mathrm{t}_{\text {tabel }} \mathrm{df}=\mathrm{n}-\mathrm{k}=100-3=97(1.660)$ dan dapat juga dilihat pada nilai $\mathrm{t}_{\text {hitung }}>\mathrm{t}$ tabel $(2.491>1,660)$ maka Ho ditolak dan $\mathrm{H}_{1}$ diterima.

\section{Pengaruh Kualitas Pelayanan Terhadap Loyalitas Konsumen (H2)}

Tabel 4.18 Hasil Uji t (Parsial)

\begin{tabular}{|c|c|c|c|c|c|c|}
\hline \multicolumn{7}{|c|}{ Coefficients $^{\mathrm{a}}$} \\
\hline & & $\begin{array}{r}\text { Unstan } \\
\text { Coeff }\end{array}$ & $\begin{array}{l}\text { lardized } \\
\text { icients }\end{array}$ & $\begin{array}{l}\text { Standardized } \\
\text { Coefficients }\end{array}$ & & \\
\hline \multicolumn{2}{|c|}{ Model } & B & Std. Error & Beta & $\mathrm{t}$ & Sig. \\
\hline \multirow[t]{2}{*}{1} & (Constant) & 8.761 & 2.476 & & 3.538 & .001 \\
\hline & Kualitas_Pelayanan & .543 & .071 & .609 & 7.594 & .000 \\
\hline & endent Variable: Loyalit & Konsume & & & & \\
\hline
\end{tabular}

Variabel kualitas pelayanan (X) berpengaruh secara positif dan signifikan terhadap loyalitas konsumen Toko Mandiri Textile Pasar Raya Padang. Hal ini terlihat dari signifikan $0,000<0,05$ nilai $t_{\text {tabel }} \mathrm{df}=\mathrm{n}-\mathrm{k}=100-3=97$ (1.660) dan dapat juga dilihat pada nilai $\mathrm{t}_{\text {hitung }}>\mathrm{t}_{\text {tabel }}(7.594>1,660)$ maka Ho ditolak dan $\mathrm{H}_{2}$ diterima.

3. Pengaruh Kepuasan Konsumen Terhadap Loyalitas Konsumen (H3)

Tabel 4.19 Hasil Uji t (Parsial)

\begin{tabular}{|c|c|c|c|c|c|c|}
\hline \multicolumn{7}{|c|}{ Coefficients $^{\mathrm{a}}$} \\
\hline & & \multicolumn{2}{|c|}{$\begin{array}{l}\text { Unstandardized } \\
\text { Coefficients }\end{array}$} & \multirow{2}{*}{$\begin{array}{c}\begin{array}{c}\text { Standardized } \\
\text { Coefficients }\end{array} \\
\text { Beta }\end{array}$} & \multirow[b]{2}{*}{$\mathrm{t}$} & \multirow[b]{2}{*}{ Sig. } \\
\hline \multicolumn{2}{|c|}{ Model } & B & Std. Error & & & \\
\hline 1 & (Constant) & 14.649 & 2.159 & & 6.785 & .000 \\
\hline & Kepuasan_Konsumen & .228 & .078 & .283 & 2.925 & .004 \\
\hline & endent Variable: Loyalitas_ & onsumen & & & & \\
\hline
\end{tabular}

Variabel kepuasan konsumen $\left(\mathrm{Y}_{1}\right)$ berpengaruh secara positif dan signifikan terhadap kepuasan konsumen Toko Mandiri Textile Pasar Raya Padang. Hal ini terlihat dari signifikan 0,004 $<0,05$ nilai $\mathrm{t}_{\text {tabel }} \mathrm{df}=\mathrm{n}-\mathrm{k}=100-3=97$ (1.660) dan dapat juga dilihat pada nilai $\mathrm{t}_{\text {hitung }}>\mathrm{t}_{\text {tabel }}(2.925>1,660)$ maka Ho ditolak dan $\mathrm{H}_{3}$ diterima.

\section{Pengaruh Kualitas Pelayanan Melalui Kepuasan Konsumen Terhadap Loyalitas Konsumen (H4)}

Tabel 4.19 Hasil Uji t (Parsial)

\begin{tabular}{|c|c|c|c|c|c|}
\hline \multicolumn{6}{|c|}{ Coefficients $^{a}$} \\
\hline & $\begin{array}{r}\text { Unstar } \\
\text { Coef }\end{array}$ & $\begin{array}{l}\text { lardized } \\
\text { cients }\end{array}$ & $\begin{array}{l}\text { Standardized } \\
\text { Coefficients }\end{array}$ & & \\
\hline Model & $\mathrm{B}$ & Std. Error & Beta & $\mathrm{t}$ & Sig. \\
\hline 1(Constant) & 3.447 & 2.985 & & 1.155 & .251 \\
\hline
\end{tabular}




\begin{tabular}{llllll}
\hline Kualitas_Pelayanan & .524 & .069 & .588 & 7.582 & .000 \\
Kepuasan_Konsumen & .285 & .096 & .229 & 2.958 & .004 \\
a. Dependent Variable: Loyalitas_Konsumen & & & & \\
\hline
\end{tabular}

Variabel kualitas konsumen (X) berpengaruh secara positif dan signifikan terhadap loyalitas konsumen Toko Mandiri Textile Pasar Raya Padang. Hal ini terlihat dari signifikan $0,000<0,05$ nilai $\mathrm{t}_{\text {tabel }} \mathrm{df}=\mathrm{n}-\mathrm{k}=100-3=97$ (1.660) dan dapat juga dilihat pada nilai $t_{\text {hitung }}>\mathrm{t}_{\text {tabel }}(7.582>1,660)$ maka Ho ditolak dan $\mathrm{H}_{4}$ diterima.

Variabel kepuasan konsumen $\left(\mathrm{Y}_{1}\right)$ berpengaruh secara positif dan signifikan terhadap loyalitas konsumen Toko Mandiri Textile Pasar Raya Padang. Hal ini terlihat dari signifikan 0,004 $<0,05$ nilai $\mathrm{t}_{\text {tabel }} \mathrm{df}=\mathrm{n}-\mathrm{k}=100-3=97$ (1.660) dan dapat juga dilihat pada nilai $\mathrm{t}_{\text {hitung }}>\mathrm{t}_{\text {tabel }}(2.958>1,660)$ maka Ho ditolak dan $\mathrm{H}_{4}$ diterima.

\subsection{Pembahasan Hasil Penelitian}

1. Pengaruh Variabel Kualitas Pelayanan Terhadap Kepuasan Konsumen Konsumen (H1)

Berdasarkan hasil analisis uji hipotesa pada tingkat kepercayaan $\alpha=5 \%$ terbukti bahwa variabel kualitas pelayanan (X) berpengaruh positif dan signifikan terhadap kepuasan konsumen konsumen Toko Mandiri Textile Pasar Raya Padang. Hal ini dibuktikan dengan nilai $t_{\text {hitung }}>t_{\text {tabel }}(2.491>1,660)$ maka Ho ditolak dan $\mathrm{H}_{1}$ diterima dan juga dilihat pengaruhnya dari analisis jalur yang dilakukan didapatkan bahwa kualitas pelayanan terhadap kepuasan konsumen sebesar 0,303. Variabel kualitas pelayanan (X) ini dapat di simpulkan bahwa kepuasan konsumen toko mandiri textile dipengaruhi oleh keberwujudan(tangible), empati (empathy), kehandalan (reliability), daya tanggap (responsiveness) dan jaminan (assurance) yang diberikan kepada konsumen sehingga konsumen merasa puas dengan fasilitas yang diberikan oleh toko mandiri textile.

\section{Pengaruh Kualitas Pelayanan Terhadap Loyalitas Konsumen (H2)}

Dari hasil analisis uji hipotesa pada tingkat kepercayaan $\alpha=5 \%$ terbukti bahwa variabel kualitas pelayanan (X) berpengaruh positif dan signifikan terhadap loyalitas konsumen konsumen Toko Mandiri Textile Pasar Raya Padang. Hal ini dibuktikan dengan nilai $t_{\text {hitung }}>t_{\text {tabel }}(7.594>1,660)$ maka Ho ditolak dan $\mathrm{H}_{2}$ diterima dan juga dilihat pengaruhnya dari analisis jalur yang dilakukan didapatkan bahwa kualitas pelayanan terhadap loyalitas pelayanan konsumen sebesar 0,229. Variabel kualitas pelayanan $(\mathrm{X})$ ini dapat di simpulkan bahwa kepuasan konsumen Toko Mandiri Textile Pasar Raya Padang dipengaruhi oleh keberwujudan (tangible), empati (empathy), kehandalan (reliability), daya tanggap (responsiveness) dan jaminan (assurance) yang diberikan kepada konsumen sehingga konsumen merasa puas dengan fasilitas yang diberikan oleh Toko Mandiri Textile Pasar Raya Padang dan melakukan pembelian ulang secara teratur, membeli antar lini produk atau jasa, mereferensikan kepada orang lain, menunjukan kekebalan terhadap tarikan dari pesaing.

\section{Pengaruh Kepuasan Konsumen Terhadap Loyalitas Konsumen (H3)}

Dari hasil analisis uji hipotesa pada tingkat kepercayaan $\alpha=5 \%$ terbukti bahwa variabel kepuasan konsumen $\left(\mathrm{Y}_{1}\right)$ berpengaruh secara positif dan signifikan terhadap kepuasan konsumen Toko Mandiri Textile Pasar Raya Padang. Hal ini terlihat dari signifikan 0,004 $<0,05$ nilai $\mathrm{t}_{\text {tabel }} \mathrm{df}=\mathrm{n}-\mathrm{k}=100-3=97(1.660)$ dan dapat 
juga dilihat pada nilai $\mathrm{t}_{\text {hitung }}>\mathrm{t}_{\text {tabel }}\left(2.925>1\right.$,660) maka Ho ditolak dan $\mathrm{H}_{3}$ diterima dan dapat juga dilihat pengaruhnya dari analisis jalur yang dilakukan didapatkan bahwa kualitas pelayanan terhadap kepuasan konsumen sebesar 0,096. Variabel kepuasan konsumen ini dapat di simpulkan bahwa kepuasan konsumen Toko Mandiri Textile Pasar Raya Padang dipengaruhi oleh kesesuaian harapan, minat berkunjung kembali, kesediaan merekomendasikan sehingga konsumen merasa puas dengan fasilitas yang diberikan oleh Toko Mandiri Textile Pasar Raya Padang dan melakukan pembelian ulang secara teratur, membeli antar lini produk atau jasa, mereferensikan kepada orang lain, menunjukan kekebalan terhadap tarikan dari pesaing.

\section{Pengaruh Kualitas Pelayanan Melalui Kepuasan Konsumen Terhadap Loyalitas Konsumen (H4)}

Dari hasil analisis uji hipotesa pada tingkat kepercayaan $\alpha=5 \%$ terbukti bahwa kualitas konsumen (X) berpengaruh secara positif dan signifikan terhadap loyalitas konsumen Toko Mandiri Textile Pasar Raya Padang. Hal ini terlihat dari signifikan $0,000<0,05$ nilai $\mathrm{t}_{\text {tabel }} \mathrm{df}=\mathrm{n}-\mathrm{k}=100-3=97$ (1.660) dan dapat juga dilihat pada nilai $\mathrm{t}_{\text {hitung }}>\mathrm{t}_{\text {tabel }}(7.582>1,660)$ maka Ho ditolak dan $\mathrm{H}_{4}$ diterima. Hal ini dapat di simpulkan bahwa kepuasan konsumen Toko Mandiri Textile Pasar Raya Padang dipengaruhi oleh keberwujudan (tangible), empati (empathy), kehandalan (reliability), daya tanggap (responsiveness) dan jaminan (assurance) yang diberikan kepada konsumen sehingga konsumen merasa puas dengan fasilitas yang diberikan oleh Toko Mandiri Textile Pasar Raya Padang.

Dari hasil analisis uji hipotesa pada tingkat kepercayaan $\alpha=5 \%$ terbukti bahwa variabel loyalitas konsumen $\left(\mathrm{Y}_{1}\right)$ berpengaruh secara positif dan signifikan terhadap kepuasan konsumen Toko Mandiri Textile Pasar Raya Padang. Hal ini terlihat dari signifikan 0,004 $<0,05$ nilai $\mathrm{t}_{\text {tabel }} \mathrm{df}=\mathrm{n}-\mathrm{k}=100-3=97$ (1.660) dan dapat juga dilihat pada nilai $\mathrm{t}_{\text {hitung }}>\mathrm{t}_{\text {tabel }}(2.958>1,660)$ maka Ho ditolak dan $\mathrm{H}_{4}$ diterima. Hal ini dapat disimpulkan bahwa kepuasan konsumen dipengaruhi oleh kesesuaian harapan yang diberikan kepada konsumen sehingga konsumen merasa puas dengan fasilitas yang diberikan oleh Toko Mandiri Textile Pasar Raya Padang dan melakukan pembelian ulang secara teratur, membeli antar lini produk atau jasa, mereferensikan kepada orang lain, menunjukan kekebalan terhadap tarikan dari pesaing.

Dan dapat juga dilihat pengaruhnya dari analisis jalur yang dilakukan didapatkan bahwa pengaruh tidak langsung (IE) kualitas pelayanan melalui kepuasan konsumen terhadap loyalitas konsumen adalah sebesar 0,029.

\section{KESIMPULAN DAN SARAN}

\subsection{Kesimpulan}

1. Terdapat pengaruh positif dan signifikan kualitas pelayanan terhadap kepuasan konsumen pada Toko Mandiri Textile Pasar Raya Padang sebesar 30,3\%.

2. Terdapat pengaruh positif dan signifikan kepuasan konsumen terhadap loyalitas konsumen pada Toko Mandiri Textile Pasar Raya Padang pasar raya Padang sebesar $22,9 \%$.

3. Terdapat pengaruh positif dan signifikan loyalitas konsumen terhadap kepuasan konsumen pada Toko Mandiri Textile Pasar Raya Padang sebesar 9,8\%.

4. Terdapat pengaruh positif dan signifikan kualitas pelayanan dalam upaya meningkatkan loyalitas konsumen terhadap kepuasan konsumen pada Toko Mandiri Textile Pasar Raya Padang dengan pengaruh tidak langsung (IE) adalah sebesar 2,9\%.

\subsection{Saran}


Penulis mencoba memberikan sumbangan pemikiran sebagai berikut :

1. Agar dapat meningkatkan kepuasan konsumen Toko Mandiri Textile Pasar Raya Padang perusahaan atau pihak manajemen harus memperhatikan faktor-faktor yang mempengaruhi kepuasan konsumen dengan mempertahankan kualitas pelayanan yang telah ada dan memberikan inovasi-inovasi baru terhadap kualitas pelayanan seperti, memberikan jaminan atas kerusakan kerusakan barang konsumen.

2. Sebaiknya Toko Mandiri Textile Pasar Raya Padang terus melakukan evaluasi dengan cara meningkatkan pemberian kualitas pelayanan kepada konsumen seperti memiliki ruangan yang nyaman, memberikan fasilitas-fasilitas lainya yang dapat mendukung kepuasan konsumen.

3. Bagi peneliti selanjutnya penulis menyarankan agar memperbanyak jumlah responden yang akan digunakan serta dilakukan dengan rentang waktu yang lebih lama. Hal ini perlu dilakukan agar hasil yang ditemukan dalam penelitian tersebut akan lebih baik dari penelitian ini.

\section{DAFTAR PUSTAKA}

Ishak, dan Luthfi. 2011. Riset Pemasaran. Jakarta: Gramedia Pustaka Utama.

Griffin, Jill. 2010. Costumer Loyalty. Jakarta: Erlangga.

Lovelock, C, and Wright, L. 2010. Principle Of Services Marketing And Management. New Jersey: Pearson Education, Inc.

Kotler, Philip. 2011. Manajemen Pemasaran. Jakarta: PT. Prenhallindo.

Kotler, P. dan Keller, K, L. 2010. Manajemen Pemasaran (Bejamin Molan, Pentj). Ed 13, Jilid 1\&2. Jakarta: Indeks.

Parasuraman. 2010. Conceptual Model of Service L. And Its Implications for Future Research, Journal of Marketing. No. 49 (Fall).

Paul. 2008. Pengantar Metode Statistik. Jakarta: LP3ES.

Sekaran, Umar. 2002. Research Methods For Business Metodologi Penelitian Untuk Bisnis. Edisi 4, Buku 1. Jakarta: Salemba Empat.

Sarwono. 2009. Analisis Regresi”.'Yogyakarta: BPFE.

Sugiyono. 2012. Metode Penelitian Pendidikan Kuantitatif, Kualitatif dan R\&D. Bandung: CV. Alfabeta.

Sugiyono. 2014. Metode Kuantitatif, Kualitatif dan R\&D. Bandung: CV. Alfabeta.

Tjiptono, Fandy. 2011. Strategi Pemasaran. Yogyakarta: Edisi Ke Empat.

Yuniar, Nugroho. 2011. Mengukur Kepuasan Pelanggan. Jakarta: PPM. 